\title{
Orgaandonatie na euthanasie
}

Tim van Smaalen, Annelieke Hof-van Smaalen, Monique van Smaalen-Croes, Wim de Jongh, Jan Bollen, Ernest van Heurn, Walther van Mook

Sinds 2012 kunnen in Nederland organen en weefsels na euthanasie gedoneerd worden. Huisartsen doen het leeuwendeel van de euthanasiemeldingen; zij zijn ook bij uitstek in de positie om potentiële orgaandonoren te identificeren. Dat stelt hen geregeld voor de keuze of zij dit ingewikkelde traject, waarvan de uitkomst onzeker is, willen ingaan. Euthanasie en orgaandonatie blijven strikt gescheiden procedures en een euthanasiewens mag nooit voortkomen uit de wens een orgaan te doneren. Slechts $10 \%$ van de euthanasiepatiënten is geschikt als orgaandonor en de donatieprocedure is intensief; toch kan het zinvol zijn het gesprek hierover aan te gaan.

Sinds 2012 kunnen in Nederland organen en weefsels na euthanasie gedoneerd worden. Het aantal donaties na euthanasie is nog relatief klein (23 tussen 2012 en 2017), maar de publieke bewustwording neemt toe. ${ }^{1-8}$ Het MUMC en Erasmus MC namen begin 2016 het initiatief tot een Handreiking orgaandonatie na euthanasie en op 8 maart 2017 beschreef de Nederlandse Transplantatie Stichting (NTS) de praktische, maatschappelijke, ethische, juridische en organisatorische aspecten van de gecombineerde procedure in de Richtlijn orgaandonatie na euthanasie. Deze richtlijnen zijn van belang voor huisartsen en specialisten Ouderengeneeskunde, omdat zij veelvuldig betrokken zijn bij de uitvoering van euthanasie.

\section{DE KERN}

- Sinds 2012 kunnen na euthanasie weefsels en organen zoals longen, lever, nieren en pancreas gedoneerd worden; in 2017 is de procedure in een richtlijn beschreven.

- Als de patiënt de mogelijkheid van orgaandonatie ter sprake brengt, kan de huisarts laagdrempelig de Nederlandse Transplantatie Stichting [NTS] consulteren.

- De NTS beheert het Donorregister en kan de huisarts in contact brengen met een transplantatiecoördinator.

- Orgaandonatie is een intensief traject voor de patiënt, diens naasten én de arts; patiënten kunnen te allen tijde hun toestemming intrekken

- Bij orgaandonatie na euthanasie moet de hele procedure plaatsvinden in een ziekenhuis.
Van de 6091 meldingen 'levensbeëindiging op verzoek of hulp bij zelfdoding' die in 2016 bij de regionale toetsingscommissies werden gedaan, waren er 5383 (88\%) afkomstig van een huisarts of van een specialist Ouderengeneeskunde. ${ }^{10}$ In termen van overleving, levensverwachting en kwaliteit van leven heeft orgaantransplantatie grote voordelen boven orgaanfunctievervangende therapieën. ${ }^{11-13} \mathrm{Er}$ is echter een permanent tekort aan geschikte donororganen en men zoekt naar manieren om dit tekort te verminderen. ${ }^{14-16}$ In 2016 waren er in Nederland 235 postmortale donoren en stonden er bijna 1100 mensen op de wachtlijst voor een donororgaan. ${ }^{17,18}$ Uit recent onderzoek blijkt dat ongeveer 10\% van de patiënten na euthanasie medisch geschikt is voor orgaandonatie; dit kan het donoraanbod dus aanzienlijk vergroten. ${ }^{19}$

Deze nascholing beschrijft wat orgaandonatie na euthanasie zal betekenen voor huisartsen en biedt handvatten voor de praktijk. Het artikel bevat achtergrondinformatie en een stappenplan voor het initiëren van de procedure en het verstrekken van de juiste informatie. De maatschappelijke, ethische en juridische dilemma's omtrent euthanasie en orgaandonatie, hoe belangrijk ook, blijven buiten beschouwing. Informatie hierover kunt $\mathrm{u}$ vinden in de eerdergenoemde richtlijn en in twee recente publicaties. ${ }^{9,20,21}$

\section{WENS TOT EUTHANASIE EN WENS TOT ORGAANDONATIE}

Een verzoek tot levensbeëindiging of hulp bij zelfdoding wordt alleen gehonoreerd indien voldaan is aan de zorgvuldigheidseisen zoals bepaald in artikel 2 van de Wet toetsing levensbeëindiging op verzoek en hulp bij zelfdoding. ${ }^{22}$ Als de patiënt tevens organen wenst te doneren dan kan dat, maar de twee procedures blijven strikt gescheiden.

Eén van de kernaanbevelingen van de huidige richtlijn is dat de patiënt in de palliatieve fase zelf de wens tot orgaandonatie moet aangeven. Die wens kan ter tafel komen voor- of nadat de zorgvuldigheidseisen rond euthanasie zijn getoetst. Gebeurt het voordat de zorgvuldigheidseisen zijn getoetst, dan hoort de arts de patiënt te vertellen dat eerst aan die eisen moet zijn voldaan alvorens de donatieprocedure kan worden opgestart. Deel 1 van de richtlijn (p. 13-15) bevat patiënteninformatie over de procedure en de vereisten. ${ }^{9}$ De arts, en later ook de SCEN-arts, zal moeten beoordelen of de wens tot euthanasie voortkomt uit de wens tot orgaandonatie.

Bij een wens tot orgaandonatie is het zinvol als de arts het Donorregister raadpleegt om een eventuele eerder vastgelegde bezwaarregistratie ongedaan te kunnen maken en te vervan- 
gen door een nieuwe schriftelijke verklaring. Het Donorregister kan telefonisch worden geraadpleegd via de NTS (0715795795).

Op dit moment beveelt de richtlijn niet aan dat de arts het initiatief neemt om orgaandonatie na euthanasie te bespreken. Maar het lijkt ons niet ondenkbaar dat de arts de patiënt over die mogelijkheid informeert, zeker als deze positief geregistreerd is. Het is aan de arts om in te schatten of de mogelijkheid tot donatie bespreekbaar is.

\section{Het is aan de arts om in te schatten of de mogelijkheid tot donatie bespreekbaar is}

\section{WAT ER GEDONEERD KAN WORDEN}

Omdat er een onderscheid is tussen orgaandonatie en weefseldonatie, wordt weefseldonatie apart besproken. Er zijn verschillende typen postmortale donoren; de [figuur] geeft een overzicht. Orgaandonoren na euthanasie behoren tot de donoren na circulatiestilstand (DCD) uit categorie III van de Maastricht-classificatie. Als de organen medisch geschikt bevonden zijn, komen longen, lever, pancreas (zowel voor orgaantransplantatie als transplantatie van de geïsoleerde eilandjes van Langerhans) en nieren in aanmerking voor donatie na euthanasie.

Orgaandonoren na euthanasie zijn vergelijkbaar met donoren met een infauste prognose bij wie de intensivecarebehandeling op een gecontroleerde manier gestaakt wordt..$^{23}$ De behande- lend arts stelt dan de dood vast op basis van een circulatiestilstand en neemt daarbij een observatieperiode van vijf minuten in acht, de zogeheten no touch-tijd. ${ }^{24} \mathrm{Bij}$ euthanasie is er geen sprake van het staken van een behandeling en stelt de arts de dood vast op basis van polsloosheid, bewusteloosheid en afwezigheid van ademhaling. Dit tijdstip kan dus verschillen van het officiële tijdstip van overlijden zoals geregistreerd door de forensisch arts na de no touch-tijd. ${ }^{24}$

\section{STAPPENPLAN EN BELANGRIJKE OVERWEGINGEN VOOR DE HUISARTS}

Deel 1 van de Richtlijn orgaandonatie na euthanasie bevat een stappenplan voor het doorlopen van een gecombineerde procedure. ${ }^{9}$ Hieronder beschrijven wij de belangrijkste onderdelen.

\section{Stap 1: aanmelding van de donor}

Nadat het onderwerp orgaandonatie na euthanasie ter sprake is gekomen, informeert de behandelend arts de patiënt zodat deze een weloverwogen keuze kan maken. De arts neemt contact op met de NTS, raadpleegt eventueel het Donorregister en verzoekt een transplantatiecoördinator contact op te nemen. De transplantatiecoördinator en de contactspecialist (een intensivist of andere aangewezen medisch specialist) assisteren bij de voorlichting aan de patiënt. Als de patiënt dit wenst, start de transplantatiecoördinator de procedure. Als eerste wordt beoordeeld of donatie mogelijk is en zo ja onder welke voorwaarden. De contactspecialist en de transplantatiecoördinator zullen alle volgende stappen begeleiden en coördineren, in samenspraak met de patiënt en de behandelend arts.

Figuur

Typen orgaandonoren en mogelijk te doneren organen na overlijden in Nederland

soort donatie

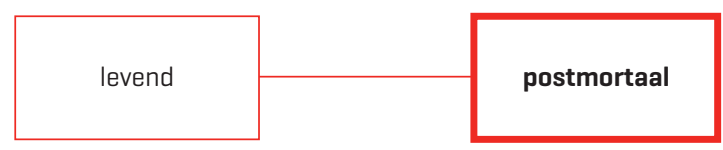

type donatie

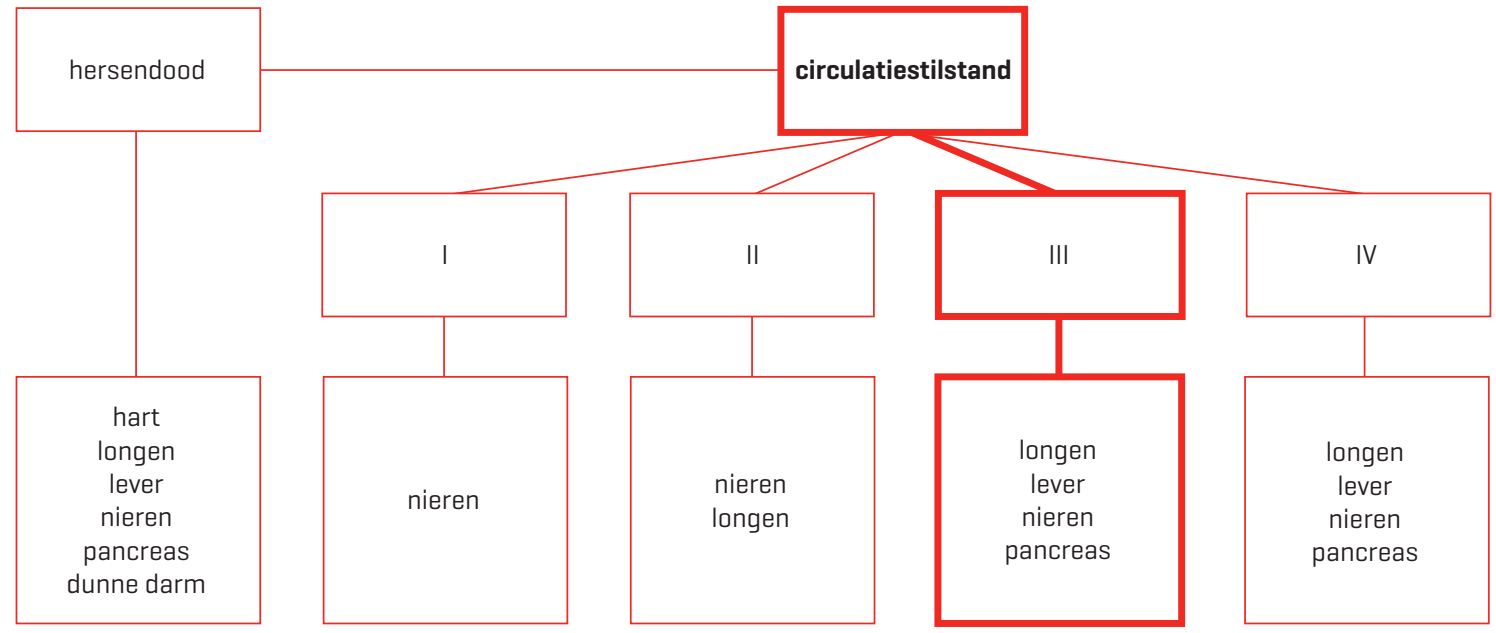

Organendonoren na euthanasie vallen binnen de geaccentueerde lijnen. 
Stap 2: beoordeling medische geschiktheid van de donor Een patiënt is medisch geschikt om te doneren indien de organen die verkregen kunnen worden van acceptabele kwaliteit zijn en het verwachte succes van de transplantatie opweegt tegen de belasting en de risico's voor de ontvanger. Uit de leeftijdscriteria voor orgaandonatie die de NTS heeft opgesteld volgt dat orgaandonoren na euthanasie niet ouder mogen zijn dan ongeveer 75 jaar [tabel 1].

$\mathrm{Na}$ de leeftijdsscreening wordt het huidige ziektebeeld en de medische voorgeschiedenis beoordeeld. Overdraagbare ziekten die een onaanvaardbaar risico vormen voor de ontvanger, zoals actieve sepsis en de meeste (actieve) maligniteiten, worden als contra-indicatie beschouwd. Een curatief behandelde maligniteit hoeft niet altijd een contra-indicatie te zijn. [Online tabel 2] geeft weer hoeveel donoren in 2016 na levensbeëindiging op verzoek of hulp bij zelfdoding mogelijk medisch geschikt waren voor orgaandonatie. Naar verwachting zal het merendeel van de medisch geschikte donoren na euthanasie een neurodegeneratieve aandoening hebben zoals amyotrofische laterale sclerose of de ziekte van Huntington. Stap 3: beoordeling van de te doneren organen Als de donor medisch geschikt lijkt, zal de transplantatiecoördinator de functies beoordelen van alle potentieel te doneren organen. Daarvoor is in elk geval bloed- en urineonderzoek noodzakelijk. Transplantatiecoördinator, transplantatiespecialist, huisarts en patiënt bepalen in overleg of aanvullend (beeldvormend) onderzoek nodig is; voor dit onderzoek zal in de dagen voor donatie een extra ziekenhuisopname noodzakelijk zijn. Enkele onderzoeken kunnen desgewenst eerder gedaan worden, maar het kan nodig zijn tijdens de opname voor donatie na euthanasie het bloed- en urineonderzoek te herhalen om de kwaliteit van de organen te beoordelen. Dan nog blijft het mogelijk dat organen op de dag van overlijden niet geaccepteerd worden voor transplantatie. Deze onzekerheid is belastend voor de patiënt. Bovendien vormen de diverse onderzoeken een grote, soms onacceptabele belasting.

\section{Tabel 1}

De leeftijdscriteria in Nederland voor orgaandonatie na hersendood en circulatiestilstand

\begin{tabular}{|c|c|c|}
\hline Orgaan & Hersendood & Circulatiestilstand \\
\hline Hart & tot circa 65 jaar & niet mogelijk \\
\hline Longen & tot circa 75 jaar & tot circa 75 jaar \\
\hline Lever & geen beperking & 1 maand tot circa 60 jaar \\
\hline Pancreas: & tot circa 60 jaar & 5 tot circa 50 jaar \\
\hline \multicolumn{3}{|l|}{ geheel orgaan } \\
\hline Pancreas: & tot circa 75 jaar & tot circa 75 jaar \\
\hline \multicolumn{3}{|l|}{ Eilandjes van Langerhans } \\
\hline Nieren & geen beperking & 5 tot circa 75 jaar \\
\hline Dunne darm & 1 tot circa 50 jaar & niet mogelijk \\
\hline
\end{tabular}

Bron: Criteria en contra-indicaties orgaandonatie 2017.25

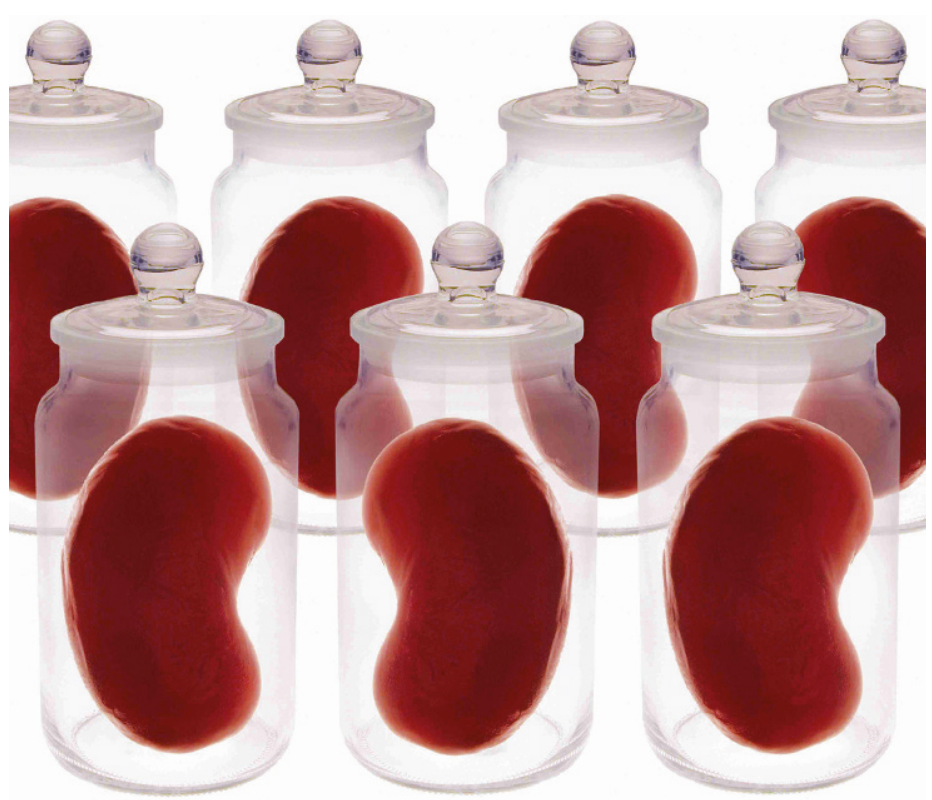

Orgaandonatie na euthanasie is een traject met een onzekere uitkomst, dat veel extra gesprekken nodig maakt en allerlei organisatorische consequenties heeft.

Foto: Getty Images

In gezamenlijk overleg moet besloten worden welke onderzoeken uitvoerbaar zijn en welke organen dan in aanmerking kunnen komen voor donatie. De kosten voor alle diagnostiek zijn niet voor rekening van de patiënt.

\section{Stap 4: ziekenhuisopname}

Orgaandonatie moet in een ziekenhuis uitgevoerd worden omdat organen zo snel mogelijk na het overlijden beschermd moeten worden tegen ischemische schade. De noodzaak van een ziekenhuisopname en de noodzaak een dag te kiezen waarop zowel de euthanasie als de orgaandonatie kunnen plaatsvinden, maken het zoeken naar een datum lastiger dan bij euthanasie

\section{Orgaandonatie en euthanasie zijn strikt gescheiden}

in de thuissituatie. De contactspecialist en transplantatiecoördinator zullen proberen de door de patiënt gewenste datum te faciliteren. Als er geen contra-indicaties bestaan en orgaandonatie mogelijk is, wordt de patiënt opgenomen op de dag van de euthanasie. Als dat nodig is, kunnen tijdens deze opname in overleg met de patiënt nog diagnostische tests plaatsvinden.

\section{Stap 5: uitvoering van de euthanasie en orgaandonatie} In het ziekenhuis kan de euthanasie worden uitgevoerd door de betrokken huisarts. De richtlijn van KNMP en KNMG schrijft voor dat de (ziekenhuis)apotheker de euthanatica direct aan de uitvoerende arts overhandigt. ${ }^{26}$ Men streeft ernaar de euthanasie uit te voeren op soortgelijke wijze als in de thuissituatie, in een aparte kamer voor patiënt, naasten en huisarts met zo veel mogelijk privacy. Ander (para)medisch 
personeel is er in principe niet bij aanwezig. De familie kan tot het moment van overlijden bij de patiënt blijven.

Een belangrijk verschil met euthanasie in de thuissituatie is de periode nadat de huisarts het overlijden heeft vastgesteld. Tijdens de no touch-tijd van vijf minuten kan de familie afscheid nemen, daarna wordt de donor zo snel mogelijk naar de operatiekamer gebracht om ischemische schade aan de organen te beperken. In de praktijk is gebleken dat familie goed kan omgaan met deze situatie als zij hierover van tevoren duidelijk is voorgelicht. Het gaat per slot van rekening om de laatste wens van de patiënt zelf. Na terugkomst van de donor uit de operatiekamer kan men nogmaals afscheid nemen; daarna wordt de overledene naar het mortuarium gebracht en neemt de begrafenisondernemer de zorg over. De overledene kan eventueel thuis worden opgebaard.

\section{FORENSISCH ONDERZOEK}

Overlijden na euthanasie is een niet-natuurlijk overlijden. De huisarts of de transplantatiecoördinator zal de forensisch arts op voorhand informeren over de geplande procedure en de forensisch arts en officier van justitie vragen het lichaam vrij te geven voor orgaandonatie. Na het overlijden en na de orgaanuitname zal de forensisch arts een schouwing komen doen.

\section{Longen, lever, pancreas en nieren kunnen gedoneerd worden}

\section{WEEFSELDONATIE}

Het doneren van hartkleppen, thoracale aorta, oogweefsel, huid en bot-, kraakbeen- en peesweefsel wordt beschouwd als weefseldonatie. Hiervoor gelden aparte leeftijdscriteria en contra-indicaties. ${ }^{27}$ Ziekten waarvan de etiologie onbekend is, zoals amyotrofische laterale sclerose en multipele sclerose, zijn momenteel een contra-indicatie. Hartkleppen en thoracale aorta kunnen worden uitgenomen tijdens de orgaandonatie; overige weefsels worden na afloop van de orgaandonatieprocedure afgenomen door een speciaal opgeleid team. ${ }^{28}$

\section{OVERWEGINGEN VOOR DE HUISARTS}

In de uitgebreide gesprekken die de huisarts voert met zijn patiënt met een neurodegeneratieve aandoening over diens levenseinde is doorgaans voldoende tijd beschikbaar. Betreft het een euthanasiewens als bepaalde grenzen zijn bereikt voor de patiënt en dit is goed uitgesproken tussen patiënt en behandelend arts, dan is er ook ruimte om, op initiatief van de patiënt, een gesprek over orgaandonatie te voeren. In situaties zoals hierboven beschreven is, na consulteren van het Donatieregister, wellicht ook een gesprek op initiatief van de arts mogelijk om de patiënt optimaal te informeren. Zaken die belastend zijn voor patiënt, zoals de onderzoeken, het verblijf en de procedure in het ziekenhuis en de belasting voor de familie, moeten goed worden besproken.

De procedure is ook lastig voor de behandelend arts, die moet

\section{Tabel 2}

Aantal meldingen van levensbeëindiging op verzoek of hulp bij zelfdoding in Nederland in 2016 en verwachte geschiktheid voor orgaandonatie op basis van de gemelde aandoeningen

\begin{tabular}{|c|c|c|}
\hline Aandoening & Aantal & Medische geschiktheid \\
\hline Maligniteiten & 4137 & ongeschikt \\
\hline Aandoeningen van het zenuwstelsel & 411 & mogelijk geschikt \\
\hline Overige aandoeningen & 104 & waarschijnlijk ongeschikt \\
\hline Multipele ouderdomsaandoeningen & 244 & waarschijnlijk ongeschikt \\
\hline Hart- en vaataandoeningen & 315 & waarschijnlijk ongeschikt \\
\hline Longaandoeningen & 214 & waarschijnlijk ongeschikt \\
\hline Dementie & 141 & mogelijk geschikt \\
\hline Psychiatrische aandoeningen & 60 & mogelijk geschikt \\
\hline Combinatie van aandoeningen & 465 & waarschijnlijk ongeschikt \\
\hline Totaal & 6091 & \\
\hline
\end{tabular}

Bij de gegeven aantallen is geen rekening gehouden met leeftijd en met daadwerkelijke geschiktheid voor orgaandonatie.

Bron: Regionale toetsingscommissies euthanasie 2017, p. 13.10

nagaan of de wens tot euthanasie geheel losstaat van de wens tot donatie en vervolgens de regie voor een deel uit handen moet geven. Orgaandonatie na euthanasie is een traject met een onzekere uitkomst, dat veel extra gesprekken nodig maakt en allerlei organisatorische consequenties heeft. De huisarts zal dit alles laten meewegen in de beslissing om het traject met een patiënt in te gaan, in de wetenschap dat die patiënt te allen tijde van donatie kan afzien zonder dat daarbij vraagtekens worden geplaatst.

\section{LITERATUUR}

1. De Vries B. Orgaandonatie na euthanasie makkelijker [internet]. NOS, 22 november 2014.

2. Redactioneel: RadboudUMC weigert orgaandonatie na euthanasie. De Volkskrant, 6 februari 2015

3. Jinek: Ziekenhuis weigert gezonde donor. KRO-NCRV, 6 februari 2015.

De rest van de literatuur staat bij dit artikel op www.henw.org.

Van Smaalen TC, Hof-van Smaalen AS, Van Smaalen-Croes MM, De Jongh W, Bollen JA, Van Heurn LW, Van Mook WN. Orgaandonatie na euthanasie. Huisarts Wet 2018;61[2]:49-52. D0I:10.1007/s12445017-1014-7.

Erasmus MC, afdeling Chirurgie, Rotterdam: T.C. van Smaalen, aios chirurgie [voorheen transplantatiecoördinator Maastricht UMC], vansmaalen@gmail.com. A.S. Hof-van Smaalen, waarnemend huisarts. M.M. van Smaalen-Croes, huisarts n.p. en SCEN-arts. Maastricht UMC: W. de Jongh, transplantatiecoördinator; J.A.M. Bollen, aios anesthesie, postgraduaat Gezondheidsrecht en gezondheidsethiek; prof.dr. W.N.K.A. van Mook, hoogleraar Professionele ontwikkeling en regionaal coördinerend donatie-intensivist. AMC/VUmc, afdeling Chirurgie, Amsterdam: prof.dr. L.W.E. van Heurn, hoogleraar Kinderchirurgie en transplantatiechirurg [lid werkgroep richtlijn Orgaandonatie na euthanasie]. Mogelijke belangenverstrengeling: niets aangegeven. 